\title{
The future is now: New United Nations' Sustainable Development Goals report provides a perspective on vector-borne diseases
}

\author{
Anna-Sofie Stensgaard, ${ }^{1}$ Laura Rinaldi, ${ }^{2}$ Robert Bergquist ${ }^{3}$ \\ ${ }^{1}$ Center for Macroecology, Evolution and Climate, GLOBE Institute, University of Copenhagen, \\ Copenhagen, Denmark; ${ }^{2}$ Department of Veterinary Medicine and Animal Production, University of Naples \\ Federico II, Naples, Italy; ${ }^{3}$ Ingerod, Brastad, Sweden
}

On January 1, 2016, the United Nations' 17 Sustainable Development Goals (SDGs) for the year 2030 came into force after its adoption in 2015. In September 2019, its Global Sustainable Development Report (GSDR) 2019 The Future is Now: Science for Achieving Sustainable Development (Independent Group of Scientists appointed by the SecretaryGeneral, 2019), was released. Meanwhile, experts from the Intergovernmental Panel on Climate Change, consisting of 200 experts from 65 countries, met in New Delhi in October 2019 to advance their work on the Working Group III contribution to the Sixth Assessment Report (SAR) due to be completed in 2022. The SAR is eagerly awaited as it deals with what many see as the root cause of the currently perceived climate change.

The GSDR account of possible future scenarios maintains, against high odds, that a world without poverty is still possible, but the authors warn that it will only occur if the relationship between people and nature improves. This is not only a fundamental requirement, but also an urgent one. With this short-term perspective, the future has already started and there is no time to lose due to increasing pollution of air, land and sea together with the potentially irreversible change of the natural environment forced by the continuing rise of the world's average temperature that may well reach $3^{\circ} \mathrm{C}$ by 2100 .

Among six SDG entry points highlighted by the GSDR as offering the most promise for achieving progress at the desired scale and speed, is SDG-3 about good health and well-being. This entails ending epidemics of malaria and neglected tropical diseases, including many vector-borne diseases (VBDs), such as African trypansomiasis, chagas, chikungunya, dengue, leishmani-

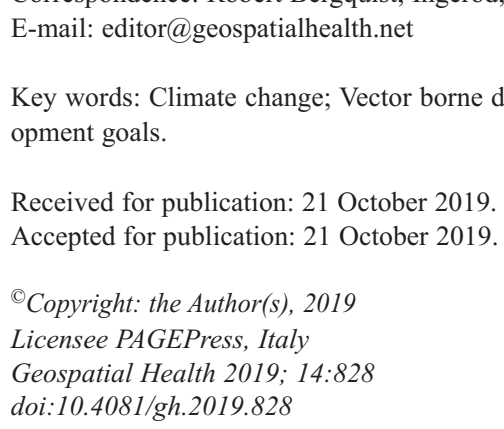
opment goals.

Received for publication: 21 October 2019.

Accepted for publication: 21 October 2019.

${ }^{\circ}$ Copyright: the Author(s), 2019

Licensee PAGEPress, Italy

Geospatial Health 2019; 14:828

doi:10.4081/gh.2019.828

Key words: Climate change; Vector borne diseases; Sustainable devel-

This article is distributed under the terms of the Creative Commons Attribution Noncommercial License (CC BY-NC 4.0) which permits any noncommercial use, distribution, and reproduction in any medium, provided the original author(s) and source are credited. asis, lymphatic filariasis, onchocerciasis, schistosomiasis, trachoma and zika. However, the achievement of this target depends in turn on concomitant progress on the other SDGs, in particular SDG-13 (climate action), as climate change is already causing a revision of the distribution of many of these diseases.

As already pointed out in a previous Editorial (Bergquist et al., 2018), numerous emerging/re-emerging VBDs of both medical and veterinary importance have already expanded their geographic ranges as a warmer world allows their vectors to enlarge their habitats. However, outbreaks in new geographical areas are also due to a variety of other causes than temperature - natural habitat destruction, environmental changes, globalisation, animal trade and migration - to mention the most important ones. Indeed, the VBDs are sensitive, both to climatic changes and environmental degradation, because of the complex ecological processes that determine the distribution and abundance of their vectors leading to increased contact between humans, vectors and non-human reservoir hosts. Undeniably, vectors pose an equally strong risk for domestic and wild animals which adds to the risk of cross contamination in contrast to other infectious diseases that do not depend on the interaction between different species and the state of the environment.

The GSDR also highlights the threat caused by the unprecedented anthropogenic loss of biodiversity, which has implications for human and animal health as the link between biodiversity and human/animal health is well-known (Aerts et al., 2018). High biodiversity has in some cases been shown to reduce the rates of VBD transmission and diminish disease risks for humans, wildlife, livestock and plants (Ostfeld, 2019) and therefore the biodiversity crisis is also a threat to human health and to achieving SDG-3. As discussed in this issue of the journal, the continuous human encroachment of natural areas in combination with climatic change are driving vampire bats into new habitats, thereby increasing the risk of rabies for livestock and people alike (Bárcenas-Reyes et al., 2019).

\section{What is being done?}

The World Health Organization (WHO), in partnership with endemic countries, non-governmental organizations (NGOs), major donors and influential pharmaceutical companies produced a Roadmap setting targets for the elimination of the majority of the most important infections (WHO, 2012). WHO has now not only extended the horizon to 2030, but also strengthened vector control (WHO, 2017). Member States have welcomed this integrated approach and adopted in 2017 the World Health Assembly resolution (70.16), which is of particular interest for schistosomiasis 
control where snail control is back on the agenda after decades of neglect.

The effects of climate change place the VBDs right at the centre of the key challenges discussed by the GSDR as temperature, humidity, water bodies and moisture govern their distribution through the combined effect on survival, movement and reproduction of the vector. Indeed, several papers related to this issue were given at the $13^{\text {th }}$ International Symposium for Geospatial Health (http://www.gnosisgis.org/index.php/meetings/), held in Liverpool, UK in collaboration with the $11^{\text {th }}$ European Congress on Tropical Medicine and International Health, 16-20 September 2019. Among these, a presentation of re-emerging of Plasmodium vivax malaria in Russia by Dr. Natalia Shartova highlighted the potential impact of the urban heat island (UHI) effect which supports current outbreaks of malaria in the Moscow region (Mironova et al., 2019). The UHI effect, caused by higher heat production in urban areas coupled with heat retention by its buildings compared to rural surroundings, increases the risk for the transmission of other VBDs in temperate regions. As highlighted by the GSDR, rapid and unplanned urbanisation is in itself a threat augmenting the stakes we are facing. However, a warmer climate might not benefit VBDs across the board in all regions of the world. This was the message from another talk concerning the impact of future climates on schistosomiasis and its intermediate snail hosts in Africa showing that future temperatures might pressure vector snails out of their thermal comfort zone in parts of subSaharan Africa, thereby reducing previously suitable habitats and paradoxically lower the risk for schistosomiasis on this continent as a whole (Stensgaard et al., 2019). Tools for genetic engineering of vectors, a new approach for VBD surveillance and response systems in times of global warming, were also mentioned by several speakers.

There is growing interest in satellite data as they can be used in lieu of classical weather station data to provide useful information for public and veterinary health disease surveillance (reviewed by Bergquist and Manda, 2019). It is not only possible to collect data in geographically limited areas regarding land surface temperatures (LST) for day and night, $\mathrm{LST}_{\text {day }}$ and $\mathrm{LST}_{\text {night, }}$ but also glean information regarding the Earth's water/energy cycle from the Global Precipitation Measurement (GPM) project that continues the Tropical Rainfall Measuring Mission. The GPM project is an international group of eight satellites that includes the DualFrequency Precipitation Radar and the GPM Microwave Imager that together provide global coverage. A major problem has been how soil moisture and hydrology act as fundamental drivers of biology and thus translate to limiting factors for parasite life cycles. Two recently launched systems, the Soil Moisture Active Passive (SMAP) satellite and the ECOsystem Spaceborne Thermal Radiometer Experiment on Space Station (ECOSTRESS) fill this gap, SMAP (https://smap.jpl.nasa.gov/) by measuring the moisture in the top $5 \mathrm{~cm}$ of soil, and ECOSTRESS algorithm (https://ecostress.jpl. nasa.gov) by gauging vegetation stress (due to lack of water) that can also stress vectors and parasite life cycles. It may soon be possible to link environmental satellites and models of vector preferences and tolerance limits to a virtual globe making this type of information accessible on demand. SMAP and ECOSTRESS data are publicly available through the NASA archive centres.

\section{Can the tide be turned?}

As the examples highlighted above show, the global effect of VBDs on the lives and well-being of humans and animals alike is immense. Despite this, there is often inadequate surveillance and a substantial lack of epidemiological data, in particular with regards to the vectors. Shortage of baseline data on vector occurrence and abundance was a common message from the presenters at the annual Geospatial Health Symposium. Yet, this type of information is imperative for predicting when and where VBDs will next emerge or re-emerge. The ecological requirements and real-time distributions of the causative agents and their vectors must not only be known to a high degree of accuracy, but the data must also be rapidly updated to match changing environmental variables. We thus need a better understanding of the ecology of new as well as old VBDs in order to develop effective prevention and control strategies; both vaccines and drugs are still far from the market for most of these infections, in many cases not even on the research bench. Strategic investment in vector ecological research is thus essential to enable us to combat the VBDs. Also, for surveillance and control to be effective and sustainable at the required speed and scale, it is imperative that new innovative approaches and tools be developed and implemented.

First and foremost, effective laboratory-based, active disease surveillance systems are needed in all countries, as are public health personnel that can respond rapidly and effectively to control epidemic transmission before it occurs. This includes training of a new generation of medical entomologists and vector ecologists, something which has been limited in recent decades due to the current focus on indoor residual spraying (IRS) insecticides and mass drug distribution that has led to a paucity of funding for vector ecological research. Strong action, both in endemic and non-endemic regions, is needed to counter this lack of skills, currently restricting the building of indigenous talent and an adequate vector expertise base.

In light of the spread of insecticide resistance, it is clear that the application of chemicals is not sustainable. However, vector control still continues to rely on IRS. As discussed in this issue of the journal by Weinberg et al. (2019) in relation to the Triatoma infestans vector of Chagas, IRS without eliminating the presence of the vector in the neighbourhood is not enough to reduce its persistence. Comprehensive programmes involving home improvement, active participation and multi-sectoral coordination are also required.

The genetic engineering of vectors is a different, but promising avenue for vector control. A new potentially potent tool in the fight against mosquito-borne infectious disease was recently demonstrated on two Chinese Islands where the world's most invasive vector species, the Asian tiger mosquito, Aedes albopictus, was very nearly eradicated using combination of radiation (Zheng et al., 2019) to sterilise the female mosquitoes, and infection with a Wolbachia bacteria that prevents the mosquito eggs from hatching.

Recent developments of a molecular method, so-called environmental DNA, that can detect traces of DNA left behind by organisms in the environment, has now been developed to detect presence of schistosome parasites and vector snails directly in water samples (Calata et al., 2019; Sengupta et al., 2019).

It has also proven useful for the detection of invasive mosquitoes (Schneider et al., 2016), and the overall potential for the application of this method for improving VBD surveillance is potentially immense due to the ease of sampling that allows large- 
scale monitoring and surveillance programmes for both vectors and pathogens in the environment. This approach goes hand in hand with the urgent need to develop targeted, risk-based surveillance strategies for the detection of pathogens early, before disease has occurred, rather than based on pets, livestock or humans as sentinels. Detecting pathogens at source (in the environment, wildlife reservoir or vector), where intervention strategies can be implemented before spill-over effects and further spread, would be of immeasurable value in today's rapidly changing environment.

\section{References}

Aerts R, Honnay O, Van Nieuwenhuyse A, 2018. Biodiversity and human health: mechanisms and evidence of the positive health effects of diversity in nature and green spaces. Br Med Bull 127:5-22.

Bárcenas-Reyes I, Nieves-Martínez DP, Cuador-Gil JQ, LozaRubio E, González-Ruiz S, Cantó-Alarcón GJ, Milián-Suazo F, 2019. Spatiotemporal analysis of rabies in cattle in central Mexico. Geospat Health 14:805.

Bergquist R, Manda S, 2019. The world in your hands: GeoHealth then and now. Geospat Health 14:779.

Bergquist R, Stengaard AS, Rinaldi L, 2018. Vector-borne diseases in a warmer world: will they stay or will they go? Geospat Health 13:699.

Calata FIC, Caranguian CZ, Mendoza JEM, Fornillos RJC, Tabios IKB, Fontanilla IKC, Leonardo LR, Sunico LS, Kawai S, Chigusa Y, Kikuchi M, Sato M, Minamoto T, Baoanan ZG, Sato MO, 2019. Analysis of environmental DNA and edaphic factors for the detection of the snail intermediate host Oncomelania hupensis quadrasi. Pathogens 8:E160.

Independent Group of Scientists appointed by the SecretaryGeneral, 2019. Global Sustainable Development Report 2019. The future is now: science for achieving sustainable development. United Nations, New York, USA. Available from: https://sustainabledevelopment.un.org/gsdr2019. Accessed: October 4, 2019.
Mironova V, Shartova N, Beljaev A, Varentsov M, Grishchenko M, 2019. Effects of climate change and heterogeneity of local climates on the development of malaria parasite (Plasmodium vivax) in Moscow Megacity Region. Int J Environ Res Public Health 26;16:E694.

Ostfeld RS, 2017. Biodiversity loss and the ecology of infectious disease. Lancet Planet Health 1:e2-e3.

Schneider J, Valentini A, Dejean T, Montarsi F, Taberlet P, Glaizot O, Fumagalli L, 2016. Detection of invasive mosquito vectors using environmental DNA (eDNA) from water samples. PLoS One 11:e0162493.

Sengupta ME, Hellström M, Kariuki HC, Olsen A, Thomsen PF, Mejer H, Willerslev E, Mwanje MT, Madsen H, Kristensen TK, Stensgaard AS, Vennervald BJ, 2019. Environmental DNA for improved detection and environmental surveillance of schistosomiasis. Proc Natl Acad Sci USA 116:8931-40.

Stensgaard AS, Vounatsou P, Sengupta ME, Utzinger J, 2019. Schistosomes, snails and climate change: current trends and future expectations. Acta Trop 190:257-68.

Weinberg D, Lanfri M, Scavuzzo CM, Abril M, Lanfri S, 2019. Evaluation and planning of Chagas control activities using geospatial tools. Geospat Health 14:786.

WHO, 2012. Accelerating work to overcome the global impact of neglected tropical diseases. A roadmap for implementation. World Health Organization, Geneva, Switzerland. Available from: https://unitingtocombatntds.org/wp-content/uploads/ 2017/11/who_ntd_roadmap.pdf. Accessed: October 4, 2019.

WHO, 2017. Global vector control response 2017-2030: a strategic approach to tackle vector-borne diseases. World Health Organization, Geneva, Switzerland. Available from: https://www.who.int/vector-control/publications/ WHO HTM_GVCR_2017.01/en/ Accessed: October 4, 2019.

Zheng X, Zhang D, Li Y, Yang C, Wu Y, Liang X, Liang Y, Pan X, Hu L, Sun Q, Wang X, Wei Y, Zhu J, Qian W, Yan Z, Parker AG, Gilles JRL, Bourtzis K, Bouyer J, Tang M, Zheng B, Yu J, Liu J, Zhuang J, Hu Z, Zhang M, Gong JT, Hong XY, Zhang Z, Lin L, Liu Q, Hu Z, Wu Z, Baton LA, Hoffmann AA, Xi Z, 2019. Incompatible and sterile insect techniques combined eliminate mosquitoes. Nature 572:56-61. 